An early version of this paper was published in Analysis 47 (1987) 80-83. The present, revised, version appears in Savas L. Tsohatzidis, Truth, Force, and Knowledge in Language: Essays on Semantic and Pragmatic Topics

(Berlin \& Boston: De Gruyter 2020).

\title{
Deontic trouble in speech act botany
}

\author{
Savas L. Tsohatzidis
}

\section{Introduction}

In the course of proposing his well-known classification of illocutionary acts into "five and only five" mutually exclusive and jointly exhaustive classes (assertives, directives, commissives, expressives, and declarations), John Searle notices a problem that acts of permission pose to him (Searle 1979: 14, 22): although he takes permissions to clearly belong to the same natural class as orders, commands, prohibitions, entreaties, etc., his classification of illocutionary acts does not seem capable of reflecting this fact, since permissions fail to exemplify what he takes to be the defining characteristic of the class of illocutionary acts to which he has allocated the others. Orders, commands, prohibitions, entreaties, etc. are, according to Searle, directive illocutionary acts, and the defining feature of these, he assumes (Searle 1979: 13), is that they are attempts by speakers to make hearers do things (or-one might add on Searle's behalf-to make hearers refrain from doing things). But, Searle observes, permissions cannot, given this definition of directives, be counted as directive illocutionary acts at all, since they are evidently not attempts by speakers to make hearers do things (nor-one might add on Searle's behalf-are they attempts by speakers to make hearers refrain from doing things). Therefore, the classification, as it stands, cannot reflect his strong pre-theoretical conviction that they belong to the same natural class as orders, commands, prohibitions, entreaties, etc.

Searle's response to this problem is not to reconsider his classificatory categories, but rather to define permission in terms of certain other uncontroversially directive acts and to thus conclude that, initial appearances notwithstanding, his classification does match his pre-theoretical convictions. The proposed definition has, at present, two variants, which are supposed to be equivalent by virtue of Searle's thesis that acts of forbidding that something be done are identical to acts of ordering that it not be done (Searle \& Vanderveken 1985: 202). According to the first variant (Searle 1979: 22), permissions that something be done are nothing else but 'illocutionary negations' (also called 'illocutionary denegations') of orders that it not be done-in other words, the illocutionary act performed in uttering a sentence like "I give you permission to leave" is the same as the illocutionary act performed in uttering a sentence like "I do not order you not to leave". According to the second variant (Searle and Vanderveken 1985: 202), permissions that something be done are nothing else but 'illocutionary negations' (also called 'illocutionary denegations') of prohibitions that it be done-in other words, the illocutionary act performed in uttering a sentence like "I give you permission to leave" is the same as the illocutionary act performed in uttering a sentence like "I do not forbid you to leave"). No 
matter which one of the variants you adopt, Searle believes, you have successfully reduced permissions to well-established species of directive illocutionary acts (notice the claim that "'permit' is the illocutionary denegation of 'forbid' and thus permission is directive", Searle \& Vanderveken 1985: 195; emphasis added); you can therefore confidently regard the classification as reflecting your pre-theoretical conviction that permissions are illocutionary acts of the same kind as orders, commands, prohibitions, entreaties, etc.

I propose to show three things: first that, even if Searle's definitions were correct, they could not possibly resolve his classification problem; second, that they are not, in fact, correct; and third, that they are not equivalent to each other.

\section{Problem A}

Searle's thesis that his definitions of permission, assuming them to be correct, succeed in showing that this act is, after all, a directive illocutionary act (cf. the just quoted claim that " "permit' is the illocutionary denegation of 'forbid' and thus permission is directive") is very confused indeed. That thesis assumes that the operation of illocutionary negation on a speech act does not change the character of this act, and in particular that the negation of an act of ordering is itself an act of the same kind as an act of ordering, or that the negation of an act of forbidding is itself an act of the same kind as an act of forbidding. However, as Searle himself has pointed out elsewhere, "illocutionary negations in general change the character of the illocutionary act" (Searle 1969: 32), and this is especially clear when the illocutionary acts negated are acts of ordering or acts of forbidding. Someone saying

(1) I do not order you not to leave.

or

(2) I do not forbid you to leave.

can hardly be described as performing an act of the same kind as an act of ordering, or an act of the same kind as an act of forbidding. He can only be described, to use terms that Searle himself had used in his general discussion of illocutionary negation (Searle 1969: 32), as refusing to perform an act of ordering or an act of forbidding, or, alternatively, as denying that an act of ordering or an act of forbidding is being performed. Therefore, if (1) and (2) are, as Searle contends, correct translations of (3),

(3) I give you permission to leave.

what Searle can claim he has achieved by devising them is not that he has shown that acts of permitting are a special sub-class of the class of acts to which acts of ordering or acts of forbidding belong (and that, therefore, they can confidently be regarded as directive illocutionary acts, given that orders and prohibitions are uncontroversially directive 
illocutionary acts), but rather that he has shown that acts of permitting are a special subclass either of the class of acts to which acts of refusing belong or of the class of acts to which acts of denying belong. And since, as Searle well knows, refusals and denials are certainly not directive illocutionary acts (in Searle's own classification, refusals are unequivocally assigned to the class of commissive illocutionary acts, and denials are unequivocally assigned to the class of assertive illocutionary acts; see Searle \& Vanderveken 1985: 183, 195), he must conclude that his proposed definitions, if they are correct, achieve precisely the contrary of what he claims they achieve: instead of enabling him to maintain his view that permissions are, after all, directive illocutionary acts, they strictly disallow him to maintain that view.

\section{Problem B}

Let us now examine whether Searle's analysis of permission is correct in itself, since someone might be tempted to adopt it while ignoring the irresolvable problems it creates for Searle's classificatory commitments. That the analysis is not, in fact, correct can be seen by noticing (among other things) that it is consistent neither with the normative prerequisites nor with the normative implications of acts of permission.

Regarding the normative prerequisites, notice that since issuing a permission (or an order, or a prohibition) requires that the person issuing the permission (or the order, or the prohibition) holds a position of authority that entitles him or her to the performance of these speech acts, a person could not coherently deny that he or she is occupying such a position of authority while attempting to perform any of these speech acts. But now observe that, of the three utterances below, it is not (4) or (5), but only (6), that is incoherent:

(4) Since I have no authority to order, permit, or forbid you anything, I do not forbid you to wear a tie.

(5) Since I have no authority to order, permit, or forbid you anything, I do not order you not to wear a tie.

(6) * Since I have no authority to order, permit, or forbid you anything, I give you permission to wear a tie.

If Searle's analysis were correct, however, (4) and (5) should be just as incoherent as (6) is. And since they are not, it follows that, contrary to what that analysis claims, permitting that something be done is not the same thing as not forbidding that it be done, or not ordering that it not be done.

Regarding the normative implications, notice that if a speaker, who has the relevant entitlement, says to a hearer,

(7) I give you permission either to leave my house or to marry my daughter. 
he eliminates from the set of the options that he presents as normatively open to the hearer the option of the latter's staying in the speaker's house without marrying the speaker's daughter. In contrast, if a similarly entitled speaker addresses a hearer with either (8) or (9),

(8) I do not order you either not to leave my house or not to marry my daughter.

(9) I do not forbid you either to leave my house or to marry my daughter.

he does not eliminate from the set of the options that he presents as normatively open to the hearer the option of the latter's staying in the speaker's house without marrying the speaker's daughter. However, if the illocutionary act performed in uttering (7) was the same as the illocutionary act performed in uttering (8) or (9), as Searle's analysis entails, it would be impossible for the utterance of $(7)$ to have normative implications that the utterance of (8) or of (9) does not have, and the contrast just noted would be nonexistent. But since the contrast clearly exists, it follows that Searle's analysis cannot be maintained.

Finally, a different kind of reason against maintaining Searle's analysis of permission emerges when one notices that, as the incoherence of (10) or (11) shows, a speaker cannot grant permission for a state of affairs that, given what he takes to be true, he ought to recognise as impossible:

(10) * Since you have never spoken to Mary, I give you permission to speak to her again.

(11) * Since you have never visited Boston, I give you permission to revisit it.

If Searle's analysis was correct, however, the following utterances should be just as incoherent as the preceding ones, since, on that analysis, their speakers would be attempting to perform exactly the same illocutionary acts that the speakers of the preceding ones cannot perform:

(12) Since you have never spoken to Mary, I do not order you not to speak to her again.

(13) Since you have never visited Boston, I do not order you not to revisit it.

But since (12) and (13), unlike (10) and (11), are perfectly coherent utterances, it follows that Searle's analysis cannot be maintained.

To sum up, Searle's analysis of permission is no more correct than his assumption that, if it were correct, it would allow him to solve his classification problem. 


\section{Problem C}

Let us finally examine whether Searle was right in believing that his two definitions of permission are equivalent, since one might be inclined to accept his reason for regarding them as equivalent - in other words, his thesis that acts of forbidding that something be done are identical to acts of ordering that it not be done-, while acknowledging that neither of them offers an acceptable analysis of permission.

The definition of acts of forbidding that was supposed to support Searle's equivalence claim may seem obvious_- "I forbid you to leave" and "I order you not to leave" can easily appear to be interchangeable-, but closer inspection of relevant evidence reveals it to be incorrect. For one thing, the definition implies that (14) and (15) can be used to perform exactly the same illocutionary act,

(14) I forbid your future children to stay in this country.

(15) * I order your future children not to stay in this country.

but this cannot be right, since (14) is perfectly meaningful whereas (15) does not even make sense. For another thing, the definition implies that (16) and (17) can be used to perform exactly the same illocutionary act,

(16) I forbid those applying for this job to have worked for the government.

(17) * I order those applying for this job not to have worked for the government.

but this cannot be right either, since (17) is nonsensical whereas (16) isn't. Finally, the definition implies that (18) and (19) can be used to perform exactly the same illocutionary act,

(18) I never give orders to you, therefore I forbid you to give orders to me.

$(19) *$ I never give orders to you, therefore I order you not to give orders to me.

but this seems hardly possible, since (19) is incoherent whereas (18) is not.

In short, Searle's claim that his two definitions of permission are equivalent is no more successful than his claim that they are correct, or that they satisfactorily resolve his classification problem. And since it is Searle's definition of acts of forbidding that is responsible for the failure of the equivalence claim, it is not only his account of permission, but also his account of prohibition, that turns out to be unacceptable. 


\section{Conclusion}

The general conclusion to be drawn is, it seems to me, this: If, as Searle and many others believe, a reasonable condition of adequacy on theories of speech acts is that they correctly analyse, and, in so doing, reflect the natural affinities between the concepts of ordering, prohibiting, and permitting, Searle's theory of speech acts fails to satisfy this condition.

\section{References}

Searle, John R. 1969. Speech acts: An essay in the philosophy of language. Cambridge: Cambridge University Press.

Searle, John R. 1979. Expression and meaning: Studies in the theory of speech acts. Cambridge: Cambridge University Press.

Searle, John R. \& Daniel Vanderveken. 1985. Foundations of illocutionary logic. Cambridge: Cambridge University Press. 